\title{
Corrigendum: Iminimycin A, the new iminium metabolite produced by Streptomyces griseus OS-3601
}

Takuji Nakashima, Rei Miyano, Masato Iwatsuki, Tatsuya Shirahata, Toru Kimura, Yukihiro Asami, Yoshinori Kobayashi, Kazuro Shiomi, George A Petersson, Yōko Takahashi and Satoshi Ōmura

The Journal of Antibiotics (2017) 70, 921; doi:10.1038/ja.2017.68

Correction to: The Journal of Antibiotics (2016) 69, 611-615; published online 13 January 2016; doi:10.1038/ja.2015.142

The authors of the above article noticed and corrected the following error in the publication of this paper.

In 'Physicochemical properties of iminimycin A (1)' under the Results section, appearance and optical rotation were wrong.
Below is the corrected version of the subsection 'Physicochemical properties of iminimycin A (1)'.

Compound 1 is readily soluble in $\mathrm{H}_{2} \mathrm{O}$ and $\mathrm{MeOH}$ and was obtained as a pale yellow oil $\left([\alpha]_{\mathrm{D}}{ }^{23.5}-34(c=0.1, \mathrm{MeOH}), \mathrm{UV}(\mathrm{MeOH}) \lambda_{\max }\right.$ (ع) 269 (2710) and 282 (2686), and IR $\nu \max (\mathrm{KBr}) \mathrm{cm}^{-1} 1682,1404$, 1203 and 1141). 